\title{
Quaternary Ammonium Bacterial Cellulose for Adsorption of Proteins
}

\author{
Teppei NIIDE ${ }^{1}$, Hikaru SHIRAKI ${ }^{2}$, Tatsuya OSHIMA ${ }^{* 2}$, Yoshinari BABA ${ }^{2}$, \\ Noriho KAMIYA ${ }^{1}$, and Masahiro GOTO ${ }^{1}$ \\ ${ }^{1}$ Department of Applied Chemistry, Kyushu University, 744 Moto-oka, Fukuoka 819-0395, Japan \\ ${ }^{2}$ Department of Applied Chemistry, University of Miyazaki, 1-1, Gakuen Kibanadai Nishi, \\ Miyazaki 889-2192, Japan
}

(Received December 19, 2009; Accepted January 26, 2010)

\begin{abstract}
Bacterial cellulose (BC) has attracted attention for preparing advanced materials due to its microfibrous structure. In this study, quaternary ammonium bacterial cellulose (QABC) as well as quaternary ammonium plant cellulose (QAPC) as adsorbents for proteins have been prepared. Introduction of the quaternary ammonium group was conducted under different conditions to determine the best conditions for modification. The fibrous structures of QABC and QAPC were quite different and determined by the starting material. The adsorption capacities of hemoglobin and an anionic dye, thymol blue, on the adsorbents QABC and QAPC which were prepared under different conditions have been investigated. QABC showed a higher adsorption capacity for hemoglobin compared with QAPC, but a lower adsorption capacity for thymol blue.
\end{abstract}

\section{Introduction}

Natural polysaccharides such as cellulose have been used in various fields to prepare functional materials because of their unique properties: nontoxicity, biocompatibility, biodegradability, hydrophilicity, and adsorption [1-4]. Recently, cellulose produced by bacteria has attracted attention for its potential in the preparation of advanced materials. Some bacteria, represented by Acetobacter xylinum, synthesize extracellular cellulose called bacterial cellulose (abbreviated as BC) [5-9]. The molecular structure of BC is an unbranched polymer of $\beta-1$, 4-linked glucopyranose residues, which is similar to that of higher plant cellulose (PC). However, the fibrous structure of BC is different from that of PC. BC is composed of microfibrils, which have a ribbon-like structure, and the thickness $\left(0.1 \times 10^{-6} \mathrm{~m}\right)$ is much smaller than that of plant cellulose $\left(10 \times 10^{-6} \mathrm{~m}\right)$. In addition, the microfibrils retain a fine network structure. As $\mathrm{BC}$ has various advantageous properties, such as high tensile strength, elasticity, and a large surface area, various 
studies for preparing novel industrial materials from BC have been conducted [10-13]. For example, a DNA separation medium has been prepared using bacterial cellulose fibrils [14].

$\mathrm{BC}$ is expected to act as an adsorptive material for various species. $\mathrm{BC}$ exhibits a larger adsorption capacity for cellobiose dehydrogenase, which is a protein showing an affinity to cellulose, compared to wood pulp cellulose [15]. Recently, the adsorption behavior of $\mathrm{Sb}(\mathrm{III})$ on $\mathrm{BC}$ was compared to that of commonly used PC [16]. The initial rate of Sb(III) adsorption on BC was faster than that on PC and was probably due to the large specific surface area. On the other hand, Wang and coworkers have developed various chemically modified BCs for the adsorption of metal ions. Carboxymethylated BC for adsorption of metal ions was synthesized by Acetobacter xylinum by adding water-soluble carboxymethylated cellulose (CMC) to the culture medium [17]. Diethylenetriamine BC and amidoximated BC have also been prepared for the adsorptive removal of $\mathrm{Cu}(\mathrm{II})$ and $\mathrm{Pb}(\mathrm{II})$ and the adsorption kinetics were studied $[18,19]$. The authors have also developed chemically modified $\mathrm{BC}$ as new adsorbents for metal ions and biomolecules such as proteins. Phosphorylation of bacterial cellulose (abbreviated as PBC) was found to be easier compared to that of cellulose powder originating from plant cellulose [20]. Furthermore, adsorption of cationic protein onto $\mathrm{PBC}$ was also examined [21]. PBC exhibited a large adsorption capacity for lysozyme compared to phosphorylated plant cellulose, which has a similar amount of phosphoric acid groups. From this precedent, chemically modified BC is expected to adsorb large quantities of proteins due to its microfibrous structure.

In the present study, quaternary ammonium bacterial cellulose (QABC) was prepared from $\mathrm{BC}$ for adsorption of proteins. The cationic adsorbent was expected to show a high adsorption capacity for proteins under basic condition. Preparation of QABC was conducted under different conditions by varying basic reagents and solvents, in order to study the best conditions for modification. Adsorption behaviors of proteins and an anionic dye on QABC as well as on quaternary ammonium plant cellulose (QAPC) which was prepared under different conditions, were investigated. The adsorption experiments help in the understanding of the effect of the fibrous structure of the cellulosic adsorbents on protein adsorption.

\section{Experimental}

\subsection{Reagents}

The starting material $\mathrm{BC}$ was prepared from "nata de coco" by grinding, washing with distilled water, and lyophilization. Cellulose powder as PC originating from a plant source was purchased from Advantec Toyo Kaisha, Ltd., Japan. The cellulose powder is made from high purity cotton cellulose which was acid treated to remove ash. Thymol blue (Fig.1) was purchased from Tokyo Kasei, Co. Ltd., Japan. All other reagents were of reagent grade and were used as received.

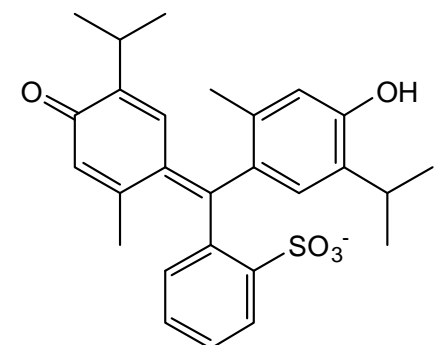

Fig. 1 Molecular structure of thymol blue. 


\subsection{Preparation of quaternary ammonium bacterial cellulose}

The dry BC was grounded and sieved to less than $200 \mu \mathrm{m}$. Preparation of QABC (Fig. 2) was examined under various conditions in order to determine the best conditions for modification. A typical procedure was as follows: $2.0 \mathrm{~g}$ of $\mathrm{BC}$ powder was soaked in $100 \mathrm{~cm}^{3}$ of N,N-dimethylformamide (DMF) along with $50 \mathrm{~cm}^{3}$ of ethylenediamine (EDA) (or trietheltetramine (TETA)). After the mixture was stirred for 24 hour, $50 \mathrm{~g}$ of (3-chloro-2-hydroxypropyl)-trimethylammonium chloride (QA) was added. The mixture was stirred at $60^{\circ} \mathrm{C}$ for 1 hour, $50 \mathrm{~g}$ of (3-chloro-2-hydroxypropyl)-trimethyl ammonium chloride was added again. The mixture was stirred at $80{ }^{\circ} \mathrm{C}$ for 2 hours. Subsequently, the mixture was stirred at $110^{\circ} \mathrm{C}$ for 24 hours. After cooling, the mixture was filtered and washed with a mixture of distilled water and $25 \%$ ethanol, followed by $0.1 \mathrm{~mol} \mathrm{dm}^{-3}$ dilute hydrochloric acid, $0.3 \mathrm{~mol}$ $\mathrm{dm}^{-3}$ dilute aqueous sodium hydroxide and finally distilled water. The product was lyophilized and ground. After sieving to less than $200 \mu \mathrm{m}, 1.6 \mathrm{~g}$ of QABC was obtained as a white powder. The quaternary ammonium plant cellulose (abbreviated as QAPC) was prepared from PC in a similar manner to $\mathrm{QABC}$, to provide a reference for $\mathrm{QABC}$. QABC and QAPC examined using a scanning electron microscope (HITACHI S-5200) to evaluate the fibrous structure. The specific surface areas of QABC, QAPC, BC, and PC were determined by the $\mathrm{N}_{2}$-BET method using a volumetric adsorption measurement instrument (BEL Japan BELSORP mini). Furthermore, X-ray diffraction (XRD) of QABC, QAPC, BC, and PC was carried out with an X-ray diffractometer (RIGAKU RINT-2000), to evaluate the crystallinity of each cellulosic material.

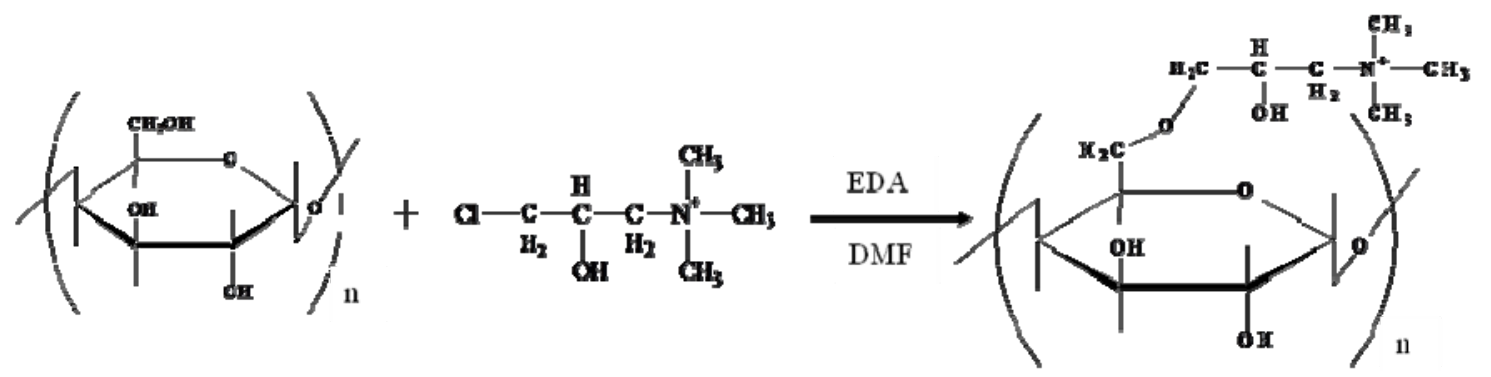

Fig. 2 Synthetic route for QABC.

\subsection{Adsorption tests}

Adsorption experiments for hemoglobin were carried out batchwise as follows: an aqueous solution

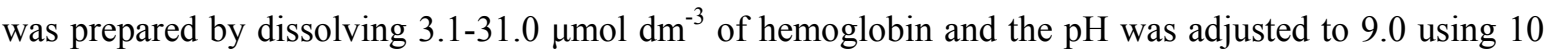
mmol dm${ }^{-3}$ of sodium phosphate buffer solution. A portion $\left(15 \mathrm{~cm}^{3}\right)$ of the aqueous solution and QABC as the adsorbent $(20 \mathrm{mg})$ were mixed in a stoppered glass tube and vigorously shaken in a thermostatregulated shaker at $30^{\circ} \mathrm{C}$. After 20 hours the adsorption had reached equilibrium and the mixture was filtered. The concentration of hemoglobin in the filtrate was determined using a UV-VIS spectrophotometer (JASCO v-660).

From the concentration of hemoglobin before and after adsorption $\left(C_{0}\right.$ and $\left.C_{e}\left[\mu \mathrm{mol} \mathrm{dm}^{-3}\right]\right)$, the 
amount of metal adsorbed (q) was calculated according to the following equation (1);

$$
q=\frac{C_{0}-C_{e}}{W} \times V\left[\mu \mathrm{mol} \mathrm{g}^{-1}\right]
$$

where $W$ is the dry mass of adsorbent in grams and $V$ is the volume of solution in $\mathrm{dm}^{3}$.

Adsorption of thymol blue on QABC and QAPC was also examined in a similar manner, using a portion $\left(15 \mathrm{~cm}^{3}\right)$ of an aqueous solution containing $0.43-2.14 \mathrm{mmol} \mathrm{dm}^{-3}$ of thymol blue and $20 \mathrm{mg}$ of the adsorbent. The concentration of thymol blue in the filtrate was determined using a UV-VIS spectrophotometer (JASCO v-660). Furthermore, adsorption experiments for hemoglobin (at pH 9), myoglobin (at pH 9), thymol blue, 1,10-phenanthroline, As(III) (at pH 13), and Sb(III) (at pH 13) using $20 \mathrm{mg}$ of adsorbent (QABC, QAPC, BC, and PC) were also carried out, in order to study the adsorption properties of each adsorbent. The concentrations of $\mathrm{As}(\mathrm{III})$ and $\mathrm{Sb}(\mathrm{III})$ before and after adsorption were analyzed using an ICP/AES spectrometer (Shimadzu ICPS-7000).

\section{Results and Discussion}

\subsection{Characteristics of quaternary ammonium bacterial cellulose}

The scanning electron micrographs of QABC and QAPC are shown in Fig. 3. As shown, the surface structure is quite different from that of QAPC from plant cellulose: a microfibrous ribbon structure can be seen on the surface of the QABC fibers. As the microfibrous structure of QABC is similar to that of the starting material $\mathrm{BC}$, the procedure for introducing quaternary ammonium groups under the experimental conditions does not influence the microfibrous structure. The specific surface areas of cellulose adsorbents calculated using the $\mathrm{N}_{2}$-BET method were $15.5 \mathrm{~m}^{2} \mathrm{~g}^{-1}$ for QABC, $1.8 \mathrm{~m}^{2} \mathrm{~g}^{-1}$ for QAPC $21.8 \mathrm{~m}^{2} \mathrm{~g}^{-1}$ for $\mathrm{BC}$, and $1.1 \mathrm{~m}^{2} \mathrm{~g}^{-1}$ for PC, respectively. The specific surface area of QABC is thus much larger compared to that of QAPC. Also, the crystallinities of QABC, QAPC, BC, and PC were evaluated using X-ray diffractometer. The crystal structure of QABC was partly destroyed compared with that of the starting material BC. By contrast, the crystal structure of QAPC was mostly retained after introduction of the quaternary ammonium group.
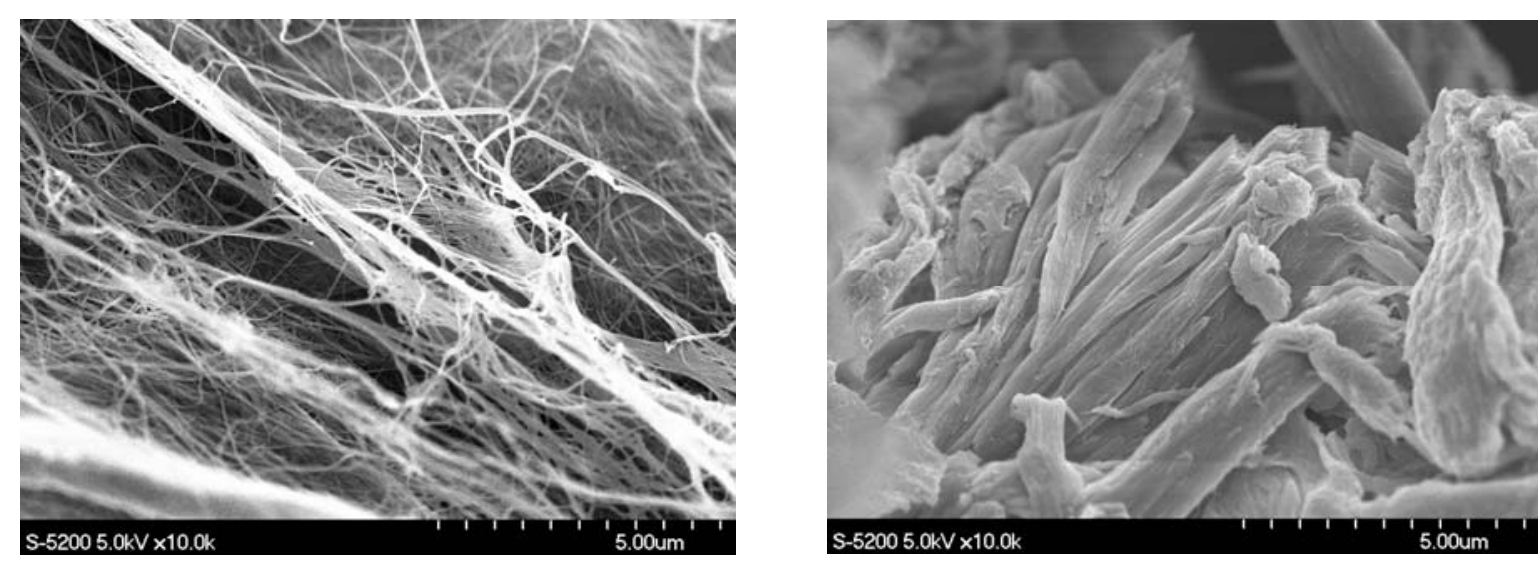

Fig. 3 Scanning electron micrographs of QABC (left) and QAPC (right) at $\times 10,000$ magnification. 


\subsection{Adsorption of hemoglobin on quaternary ammonium bacterial cellulose}

The dependence of $\mathrm{pH}$ for the adsorption of hemoglobin onto $\mathrm{BC}$ and $\mathrm{QABC}$ is shown in Fig. 4. The adsorption of hemoglobin on $\mathrm{BC}$ was quite small. By contrast, adsorption of hemoglobin on $\mathrm{QABC}$, in which a cationic quaternary ammonium group was introduced, increased with increasing $\mathrm{pH}$ and reached a maximum value under basic conditions. As the isoelectric point of hemoglobin is about 6.8 , hemoglobin exists as an anionic species under basic conditions. Thus QABC was found to act as a cationic adsorbent which captures proteins such as hemoglobin via electrostatic interaction.

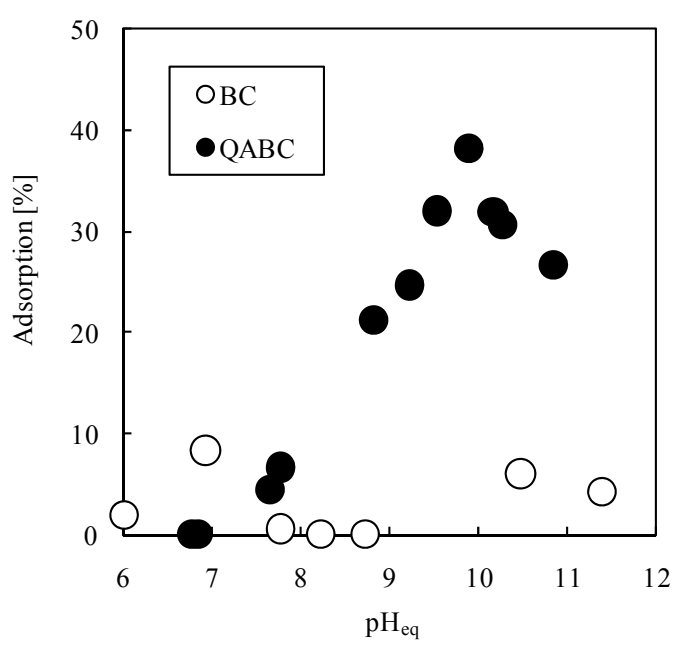

Fig. 4 Adsorption profiles for hemoglobin onto BC and $\mathrm{QABC}$ as a function of $\mathrm{pH}$ : adsorbent; $10 \mathrm{mg}$, volume; $15 \mathrm{~cm}^{3}$.

\subsection{Adsorption capacity of quaternary ammonium bacterial cellulose for hemoglobin}

Figure 5 shows adsorption isotherms for hemoglobin onto QABC and QAPC, which were prepared under the same conditions from $\mathrm{BC}$ and $\mathrm{PC}$, respectively. As the amounts of adsorption onto $\mathrm{QABC}$ and QAPC were quite different, it is likely that the amount of the quaternary ammonium groups introduced

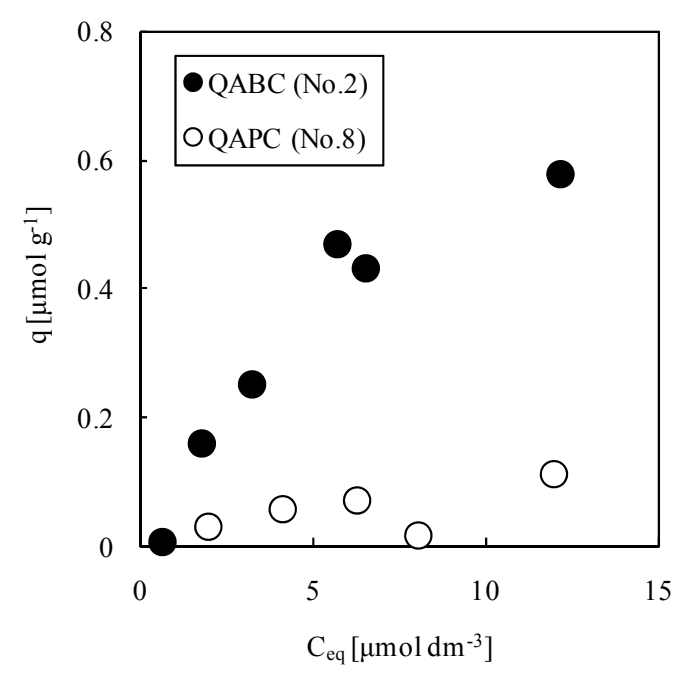

Fig. 5 Adsorption isotherms for hemoglobin on QABC (No.2 in Table 1) and QAPC (No.8 in Table 1) at $30^{\circ} \mathrm{C} \cdot \mathrm{pH}_{\text {ini }} 9.0$, adsorbent, $20 \mathrm{mg}$, volume $=15 \mathrm{~cm}^{3},[\text { hemoglobin }]_{\mathrm{ini}}=0.2-2.0 \mathrm{~g} \mathrm{dm}^{-3}$.

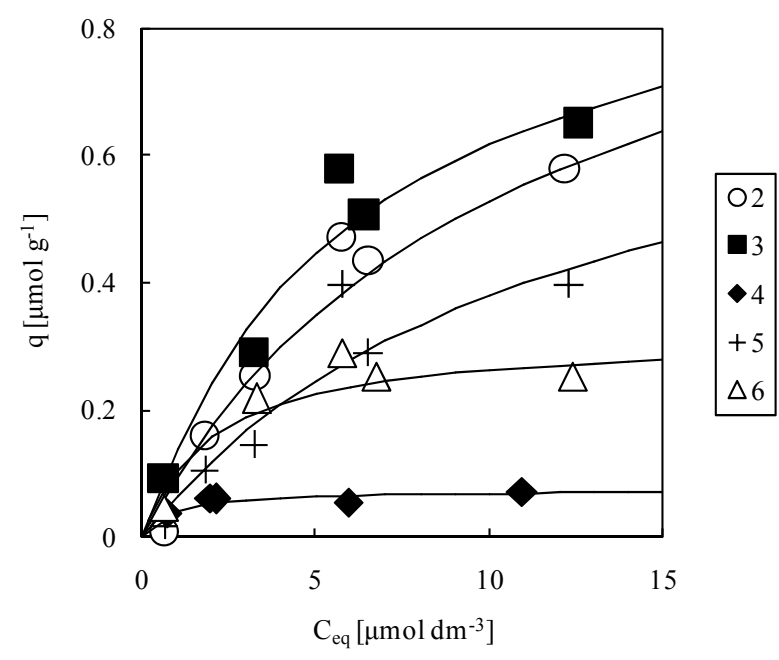

Fig. 6 Adsorption isotherms for hemoglobin on QABC adsorbents (No.2-6 in Table 1) at $30^{\circ} \mathrm{C}$. $\mathrm{pH}_{\text {ini }}$ 9.0, adsorbent, $20 \mathrm{mg}$, volume $=15 \mathrm{~cm}^{3}$, $[\text { hemoglobin }]_{\text {ini }}=0.2-2.0 \mathrm{~g} \mathrm{dm}^{-3}$. 
on QABC is larger than that for QAPC prepared under the same conditions. Figure 6 shows adsorption isotherms for hemoglobin onto QABCs, which are prepared under different conditions. The amount of adsorption of hemoglobin on QABCs increases with increasing hemoglobin concentration. The equilibrium experimental data were correlated with the Langmuir isotherm model in order to determine the maximum adsorption capacity of hemoglobin on QABC $\left(q_{\max }\right)$. The Langmuir model assumes monolayer adsorption as shown in the following equation (2):

$$
\frac{C e}{q}=\frac{C_{e}}{q_{\max }}+\frac{1}{q_{\max } K_{\mathrm{L}}}
$$

Table 1 Reactive conditions for preparing adsorbents (QABC; No. 1-7, QAPC; No. 8-13) and the maximum adsorption capacities for hemoglobin and thymol blue on each adsorbent.

\begin{tabular}{|c|c|c|c|c|c|c|c|}
\hline \multicolumn{6}{|c|}{ Conditions of preparation of QABC and QAPC ${ }^{*}$} & \multirow{2}{*}{$\begin{array}{l}q_{\max } \text { for Thymol } \\
\text { Blue }\left[\mu \mathrm{mol} \mathrm{g}^{-1}\right]\end{array}$} & \multirow{2}{*}{$\begin{array}{c}q_{\max } \text { for Hemoglobin } \\
{\left[\mu \mathrm{mol} \mathrm{g}^{-1}\right]}\end{array}$} \\
\hline No. & base & $\begin{array}{l}\text { Amount } \\
\text { of base }\end{array}$ & $\begin{array}{c}\text { Amount } \\
\text { of QA }\end{array}$ & Solvent & $\begin{array}{l}\text { Starting } \\
\text { material }\end{array}$ & & \\
\hline 1 & EDA & $50\left[\mathrm{~cm}^{3}\right]$ & $75[\mathrm{~g}]$ & DMF & $\mathrm{BC}$ & - & 5.07 \\
\hline 2 & EDA & $50\left[\mathrm{~cm}^{3}\right]$ & $25[\mathrm{~g}]$ & DMF & $\mathrm{BC}$ & 2.62 & 1.08 \\
\hline 3 & EDA & $50\left[\mathrm{~cm}^{3}\right]$ & $25[\mathrm{~g}]$ & DMSO & $\mathrm{BC}$ & 2.72 & 1.00 \\
\hline 4 & EDA & $50\left[\mathrm{~cm}^{3}\right]$ & $25[\mathrm{~g}]$ & Pyridine & $\mathrm{BC}$ & 1.66 & 0.073 \\
\hline 5 & EDA & $50\left[\mathrm{~cm}^{3}\right]$ & $25[\mathrm{~g}]$ & Methanol & $\mathrm{BC}$ & 1.36 & 0.841 \\
\hline 6 & EDA & $50\left[\mathrm{~cm}^{3}\right]$ & $25[\mathrm{~g}]$ & 2-propanol & $\mathrm{BC}$ & 0.837 & 0.315 \\
\hline 7 & TETA & $50\left[\mathrm{~cm}^{3}\right]$ & $25[\mathrm{~g}]$ & DMF & $\mathrm{BC}$ & 0.272 & 0.642 \\
\hline 8 & EDA & $50\left[\mathrm{~cm}^{3}\right]$ & $25[\mathrm{~g}]$ & DMF & $\mathrm{PC}$ & 12.8 & 0.348 \\
\hline 9 & EDA & $50\left[\mathrm{~cm}^{3}\right]$ & $25[\mathrm{~g}]$ & DMSO & $\mathrm{PC}$ & 16.5 & 0.071 \\
\hline 10 & EDA & $50\left[\mathrm{~cm}^{3}\right]$ & $25[\mathrm{~g}]$ & Pyridine & $\mathrm{PC}$ & 12.8 & 0.062 \\
\hline 11 & EDA & $50\left[\mathrm{~cm}^{3}\right]$ & $25[\mathrm{~g}]$ & 2-propanol & $\mathrm{PC}$ & 33 & 0.546 \\
\hline 12 & $\mathrm{NaOH}$ & $50\left[\mathrm{~cm}^{3}\right]$ & $25[\mathrm{~g}]$ & Methanol & PC & 41.2 & 0.753 \\
\hline 13 & urea & $50[\mathrm{~g}]$ & $25[\mathrm{~g}]$ & DMF & $\mathrm{PC}$ & 1.73 & 0.105 \\
\hline
\end{tabular}

*Common conditions are as follows: amount of cellulose, $0.3 \mathrm{~g}$; solvent, $30 \mathrm{~cm}^{3}$; reaction time. 
where $q$ denotes the amount of hemoglobin adsorbed on $\mathrm{QABC}\left[\mu \mathrm{mol} \mathrm{g}^{-1}\right], C_{e}$ denotes the equilibrium concentration of hemoglobin in the aqueous solution, and $K_{L}$ denotes the adsorption equilibrium constant $\left[\mathrm{L} \mu \mathrm{mol}^{-1}\right]$. In a similar manner, the maximum adsorption capacity of thymol blue on each adsorbent was calculated from the Langmuir equation (2) for the adsorption isotherm of thymol blue. The anionic dye, thymol blue, was used as a model material as it is a smaller molecule compared with hemoglobin and should be adsorbed on cationic adsorbents via electrostatic interaction. The amount of thymol blue adsorption partly reflects the degree of substitution of the QA group onto the adsorbents. The maximum adsorption capacities of hemoglobin and thymol blue on adsorbents QABC and QAPC, as well as the reactive conditions for preparing adsorbents are summarized in Table 1. Additionally, the relationship between the adsorption capacity of thymol blue and the adsorption capacity of hemoglobin onto QABCs and QAPCs is plotted in Fig. 7. The amount of adsorption increases with increasing amounts of QA during preparation (No. 1 and 2). The solvent for the preparation of QABC is also important for effective modification (No. 2 and 6): DMF and DMSO (dimethyl sulfoxide) are more favorable for preparation of QABC. As shown in Table 1, it is apparent that QABC shows a larger adsorption capacity for hemoglobin than QAPC prepared under the same conditions. The result suggests that the degree of substitution by quaternary ammonium groups is influenced by the morphology of the cellulose, which differs according to the origin of cellulose. As the $\mathrm{BC}$ microfibril is much thinner than the fiber of plant cellulose, modification of $\mathrm{BC}$ using QA proceeds easier than that of $\mathrm{PC}$, probably due to the easier accessibility for the reagents. The result is similar to that shown in the preparation of phosphorylated bacterial cellulose [20]. It should be noted that the adsorption behaviors of QABC and QAPC are different as shown in Fig. 7. For both adsorbents QABC and QAPC, the $q_{\max }$ values for hemoglobin increases with increasing $q_{\max }$ values for thymol blue. However, the maximum adsorption capacity for thymol blue on QABC is much smaller that on QAPC, despite the larger surface area and larger adsorption capacity for hemoglobin.

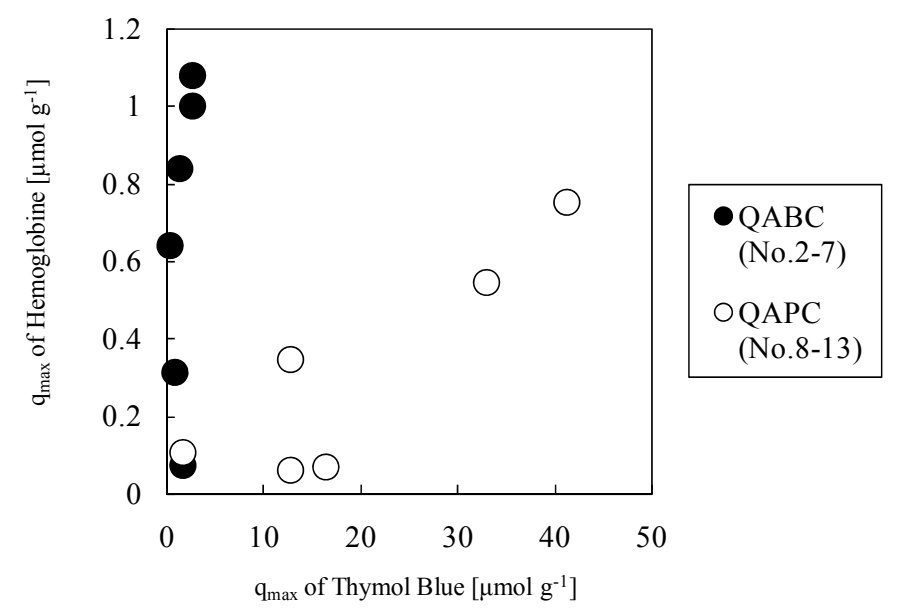

Fig. 7 Relationship between the adsorption capacity for thymol blue and the adsorption capacity for hemoglobin onto QABCs (No.2-6 in Table 1) and QAPCs (No.8-13 in Table 1). 
In order to study adsorption properties of each adsorbent, adsorption tests for various materials, which are different in molecular weight, were carried out. $\mathrm{Sb}$ (III) is found to be adsorbed on cellulosic materials [16, 22]. Thymol blue is a hydrophobic material and is present in an anionic state. 1,10-Phenanthroline is also a hydrophobic material but is not present in an anionic state. The adsorption behaviors of such materials would provide information on the important factors for adsorption on the adsorbents, such as size, hydrophobicity, and ionicity. Table 2 shows the adsorption percentages of various materials on QABC, QAPC, BC, and PC. QABC exhibited a much higher adsorption percentage for the proteins hemoglobin and myoglobin compared with QAPC, BC, and PC. Sb(III) and As(III) were also adsorbed on each adsorbent, however, differences in adsorption percentages were not so high compared with those of the adsorption percentages for proteins. On the other hand, the adsorption percentage of thymol blue on QAPC was much higher than that on QABC. However, the starting material $\mathrm{BC}$ exhibits a much higher adsorption for thymol blue as well as 1,10-phenanthroline, compared with PC. The results suggest that the surface properties of QABC, especially hydrophobicity, were altered from that of the original material $\mathrm{BC}$ by the chemical modification. On the basis of these results, QABC prepared from bacterial cellulose appears to be a favorable adsorbent for proteins compared with QAPC prepared from plant cellulose.

Table 2 Adsorption of various materials on QABC, QAPC, BC, and PC*.

\begin{tabular}{|c|c|c|c|c|c|c|c|}
\hline \multirow{3}{*}{ Adsorbent } & material & hemoglobin & myoglobin & thymol blue & $\begin{array}{c}\text { 1,10-phenan } \\
\text { throline }\end{array}$ & As(III) & $\mathrm{Sb}$ (III) \\
\hline & M.W. (A.W.) & 64,500 & 17,200 & 466 & 180 & (74.9) & (121.7) \\
\hline & initial conc. & $\begin{array}{c}6.20 \\
{\left[\mu \mathrm{mol} \mathrm{dm}{ }^{-3}\right]}\end{array}$ & $\begin{array}{c}23.3 \\
{\left[\mu \mathrm{mol} \mathrm{dm}{ }^{-3}\right]}\end{array}$ & $\begin{array}{c}0.22 \\
{\left[\mathrm{mmol} \mathrm{dm}^{-3}\right]}\end{array}$ & $\begin{array}{c}0.50 \\
{\left[\mathrm{mmol} \mathrm{dm}^{-3}\right]}\end{array}$ & $\begin{array}{c}0.12 \\
{\left[\mathrm{mmol} \mathrm{dm}^{-3}\right]}\end{array}$ & $\begin{array}{c}0.12 \\
{\left[\mathrm{mmol} \mathrm{dm}^{-3}\right]}\end{array}$ \\
\hline QABC & \multirow{4}{*}{$q\left[\mathrm{mmol} \mathrm{g}^{-1}\right]$} & $88.0 \times 10^{-3}$ & $423 \times 10^{-3}$ & 0.249 & 0 & 0.456 & 2.87 \\
\hline QAPC & & $3.88 \times 10^{-3}$ & $22.8 \times 10^{-3}$ & 3.45 & 0.013 & 0.320 & 1.65 \\
\hline $\mathrm{BC}$ & & $0.68 \times 10^{-3}$ & $9.32 \times 10^{-3}$ & 3.25 & 0.22 & 0.457 & 2.09 \\
\hline $\mathrm{PC}$ & & $0.53 \times 10^{-3}$ & $6.87 \times 10^{-3}$ & 0 & 0 & 0.566 & 1.88 \\
\hline
\end{tabular}

*Common conditions are as follows: adsorbent, $20 \mathrm{mg}$, volume $=15 \mathrm{~cm}^{3}$.

\section{Conclusions}

In the present study, quaternary ammonium groups were introduced to bacterial cellulose in order to develop a new absorbent for proteins. The microfibrous structure of the modified bacterial cellulose was mostly retained after chemical modification. A model protein, hemoglobin, was adsorbed on the quaternary ammonium bacterial cellulose under basic conditions via electrostatic interaction. The adsorption capacity for hemoglobin on quaternary ammonium bacterial cellulose is higher than that on quaternary ammonium plant cellulose which was prepared under the same conditions. Quaternary ammonium bacterial cellulose exhibited the selectivity for proteins over other materials. Therefore, 
quaternary ammonium bacterial cellulose is proposed as a new adsorptive material for relatively large biomolecules on the basis of its large surface area.

\section{Acknowledgment}

This work was partly financed in the interest of innovative technology and advanced research in evolutional areas with support from the Ministry of Education, Science, Sports and Culture of Japan. T. O. was supported by a Grand-in-Aid for Young Scientists (B, No. 21760613) from the Ministry of Education, Science, Sports and Culture of Japan.

\section{References}

1) M. N. V. R. Kumar, React. Funct. Polym., 46, 1 (2000).

2) A.K. Mohanty, M. Misra, G. Hinrichsen, Macromol. Mater. Eng., 276/277, 1 (2000).

3) D. Klemm, B. Heublein, H.P. Fink, A. Bohn, Angew. Chem. Int. Ed., 44, 3358 (2005).

4) D. W. O’Connell, C. Birkinshaw, T. F. O’Dwyer, Bioresour. Technol., 99, 6709 (2008).

5) S. Yamanaka, K. Watanabe, N. Kitamura, M. Iguchi, S. Mitsuhashi, Y. Nishi, M. Uryu, J. Mater. Sci., 25, 3141 (1989).

6) E.J. Vandamme, S. DeBaets, A. Steinbuchel, Biopolymers: Polysaccharides I : Polysaccharides from Prokaryotes, WILEY-VCH, (2003).

7) M. Iguchi, S. Yamanaka, A. Budhiono, J. Mater. Sci., 35, 261 (2000).

8) D. Klemm, D. Schumann, U. Udhardt, S. Marsch, Prog. Polym, Sci., 26, 1561 (2001).

9) E. E. Brown, M. P. G. Laborie, Biomacromolecules, 8, 3074 (2007).

10) H. Yano, J. Sugiyama, A.N. Nakagaito, M. Nogi, T. Matsuura, M. Hikita, K. Handa, Adv. Mater., 17, 153 (2005).

11) M. Tabuchi, K. Kobayashi, M. Fujimoto, Y. Baba, Lab Chip, 5, 1412 (2005).

12) V. Dubey, L. K. Pandey, C. Saxena, J. Membr. Sci., 251, 131 (2005).

13) W. Czaja, A. Krystynowicza, S. Bieleckia, R. M. Brown Jr., Biomaterials, 27, 145 (2006).

14) M. Tabuchi, Y. Baba, Anal. Chem., 77, 7090 (2005).

15) H. Ougiya, N. Hioki, K. Watanabe, Y. Morinaga, F. Yoshinaga, M. Samejima, Biosci. Biotechnol. Biochem., 62, 1880 (1998).

16) A. Suetsugu, T. Oshima, H. Fujiwara, K. Ohe, Y. Baba, J. Ion Exchange, 18, 186 (2007).

17) S. Chen, Y. Zou, Z. Yan,W. Shen, S. Shi, X. Zhang, H. Wang, J. Hazad. Mater., 161, 1355 (2009).

18) W. Shen, S. Chen, S. Shi, X. Li, X. Zhang, W. Hu, H. Wang, Carbohydr. Polym., 75, 110 (2009).

19) S. Chen, W. Shen , F. Yu, H. Wang, Polym. Bull., 63, 283 (2009).

20) T. Oshima, K. Kondo, K. Ohto, K. Inoue, Y. Baba, React. Funct. Polym., 68, 376 (2008).

21) T. Oshima, S. Taguchi, H. Fujiwara, K. Ohe, Y. Baba, J. Ion Exchange, 18, 204 (2007).

22) K. Uezu, H. Kawakita, J. Ion Exchange, 16, 173 (2005). 